\title{
RESEARCH
}

Open Access

\section{Post-traumatic stress symptoms in hemodialysis patients with MERS-CoV exposure}

\author{
A Jin Cho ${ }^{1 \dagger}{ }^{+}$, Hong-Seock Lee ${ }^{2 \dagger}$, Young-Ki Lee ${ }^{1 *}$, Hee Jung Jeon ${ }^{1}$, Hayne Cho Park ${ }^{3}$, Da-Wun Jeong ${ }^{4}$, \\ Yang-Gyun Kim ${ }^{4}$, Sang-Ho Lee ${ }^{4}$, Chang-Hee Lee ${ }^{5}$, Kyung Don Yoo ${ }^{6}$ and Ae Kyeong Wong ${ }^{2}$
}

\begin{abstract}
Background: Post-traumatic stress symptoms can occur in patients with medical illness. During the Middle East Respiratory Syndrome (MERS) outbreak in South Korea in 2015, some dialysis patients in three centers who were incidentally exposed to patients or medical staff with confirmed MERS-CoV infection were isolated to interrupt the spread of the infection. We aimed to investigate post-traumatic stress symptoms and risk factors among these patients.
\end{abstract}

Materials and methods: In total, 116 hemodialysis (HD) patients in contact with MERS-CoV-confirmed subjects were isolated using three strategies, namely, single room isolation, cohort isolation, and self-quarantine. We used the Impact of Event Scale-Revised-Korean (IES-R-K) to examine post-traumatic stress symptoms at 12 months after the isolation period.

Results: Of the 116 HD patients, 27 were lost to follow-up. Of the 89 patients, 67 (75.3\%) completed the questionnaires. Single room isolation was used on 40 (58.8\%) of the patients, cohort isolation on 20 (29.4\%), and self-imposed quarantine on $8(11.8 \%)$. In total, $17.9 \%$ of participants $(n=12)$ reported post-traumatic stress symptoms exceeding the IES-R-K's cutoff point ( $\geqq 18$ ). Prevalence rates of IES-R-K $\geqq 18$ did not differ significantly according to isolation method. However, isolation duration was linearly associated with the IES-R-K score (standardized $\beta$ coefficient $-0.272, P=0.026$ ). Scores in Avoidance, Emotional numbing and Dissociation subscale were higher in patients with longer isolation period.

Conclusion: MERS was a traumatic experience for quarantined HD patients. IES-R-K scores were not significantly different by isolation methods. However, short isolation was associated with post-traumatic stress symptoms.

Keywords: Post-traumatic stress symptom, Hemodialysis, Middle East respiratory syndrome

\footnotetext{
* Correspondence: km2071@naver.com

${ }^{+} \mathrm{A}$ Jin Cho and Hong-Seock Lee contributed equally to this work.

1 Department of Internal Medicine, Kangnam Sacred Heart Hospital, Hallym University College of Medicine, 1, Singil-ro, Yeongdeungpo-gu, Seoul 07441 South Korea

Full list of author information is available at the end of the article
}

C The Author(s). 2020 Open Access This article is licensed under a Creative Commons Attribution 4.0 International License, which permits use, sharing, adaptation, distribution and reproduction in any medium or format, as long as you give appropriate credit to the original author(s) and the source, provide a link to the Creative Commons licence, and indicate if changes were made. The images or other third party material in this article are included in the article's Creative Commons licence, unless indicated otherwise in a credit line to the material. If material is not included in the article's Creative Commons licence and your intended use is not permitted by statutory regulation or exceeds the permitted use, you will need to obtain permission directly from the copyright holder. To view a copy of this licence, visit http://creativecommons.org/licenses/by/4.0/. The Creative Commons Public Domain Dedication waiver (http://creativecommons.org/publicdomain/zero/1.0/) applies to the data made available in this article, unless otherwise stated in a credit line to the data. 


\section{Introduction}

During the outbreak of the Middle East Respiratory Syndrome coronavirus (MERS-CoV) in South Korea in 2015, 186 confirmed cases were reported, including one patient with maintenance hemodialysis (HD); 36 (19.4\%) of the patients died. In the course of coping with MERS$\mathrm{CoV}, 16,752$ people were quarantined. Some dialysis patients in three HD units were incidentally exposed to patients or healthcare workers with confirmed MERS$\mathrm{CoV}$ infection. To interrupt the spread of MERS-CoV, these individuals were isolated from the community during the outbreak.

A life-threatening physical illness can lead to various psychological symptoms after recovery. In 2003, severe acute respiratory syndrome (SARS) spread across 30 countries, and those who were infected experienced social stigma and reported mental health problems such as anxiety, depression, and post-traumatic stress disorder (PTSD) [1-4]. In Hong Kong, the mental health of 1394 SARS survivors was assessed; $47.8 \%$ of the sampled participants experienced PTSD symptoms after recovery, and $25.6 \%$ of those who had PTSD symptoms continued experiencing mental health issues up to 30 months after the outbreak [5].

Patients with HD have a high risk of accompanying psychiatric illnesses such as depression, anxiety, and stress symptoms [6-8], and previous exposure to trauma indicates a greater risk of stress symptoms from a subsequent trauma [9]. In the outbreak of MERS-CoV in South Korea, some HD patients were quarantined irrespective of their own will to prevent secondary MERS-CoV infection. Fortunately, no further patients were infected by MERS-CoV; however, the possibility of a life-threatening infection and quarantine can be more traumatic to patients with chronic kidney disease than to the general population. The experience of those placed under quarantine in terms of compliance, emotional response, and psychological impact remains under-researched in HD patients. This study examined post-traumatic stress symptoms and associated factors among HD patients who were exposed to MERS-CoVinfected patients and isolated for a certain period.

\section{Methods}

\section{Participants}

A total of $116 \mathrm{HD}$ patients were isolated in Kyung Hee University at Kangdong, Gangeung Medical Center and Kangdong Sacred Heart Hospital during the outbreak of MERS in Korea. Among those, 89 patients were included in this study because 27 were lost to follow-up at 12 months after quarantine. One HD patient and a head nurse in the HD room at the first two hospitals were confirmed to be MERS-CoV-infected. As a result, 107 HD patients at these two hospitals were suspected to have been exposed to the confirmed cases. In the third hospital, $9 \mathrm{HD}$ patients were exposed to MERS-CoV from a confirmed case outside HD units. All three HD units performed isolation practice to prevent the further spread of MERS-CoV among maintenance HD patients.

\section{Isolation practice}

According to the "Middle East respiratory syndrome clinical practice guideline for HD facilities" by the Korean Society of Nephrology during the MERS-CoV outbreak in 2015, a patient in close contact with a MERS patient, without fever or respiratory symptoms, would be subjected to hospitalized quarantine for 14 days since last exposure [10]. Close contact refers to a receiver of dialysis who was in the same place, at the same time as a suspected or confirmed MERS patient in the symptomatic period [11]. Asymptomatic casual contacts should be subjected to cohort isolation for 14 days after exposure and closely monitored for any suspicious symptoms. Casual contact refers to those who received dialysis on the same day, in the same room as a patient with suspected or confirmed MERS-CoV infection, but at different times and on different beds during the symptomatic period, without having worn appropriate personal protective equipment. Hospitalized quarantine was defined as single room or cohort isolation. Patients isolated in a single room received dialysis in their own rooms installed with dialysis machines. "Cohort isolation" is a method of hospitalized quarantine during HD treatment, in a shared HD room. Self-quarantine applied to a patient who received dialysis on a different day from dialysis date of MERS-CoV confirmed case or to patients who were exposed to MERS-CoV from a confirmed case outside HD units and had no respiratory symptoms. The patient was monitored for the development of fever or respiratory symptoms during quarantine.

\section{Clinical data and measures}

Demographic information including age, gender, HD duration, history of diabetes mellitus, and previous cardiovascular diseaselaboratory data including hemoglobin, albumin, and hsCRP were collected at the time of enrollment.

A survey was conducted at 12 months after the isolation period. Post-traumatic stress symptoms were assessed with the Impact of Event Scale-Revised-Korean (IES-R-K), which showed good reliability and validity for the assessment of PTSD symptom severity [12]. The scale consisted of the following four factors: intrusion; avoidance; hyperarousal; and sleep disturbance, emotional numbing, and dissociation. A five-point Likert scale was used with response options ranging from "0 = Never" to " $4=$ Very often." A high total score represented high severity of the symptoms; so, a total score of 
18 or more was used as a cut-off [12]. The alpha coefficient for this sample was 0.873 .

\section{Statistics}

The data are expressed as mean \pm standard deviation. Comparisons of continuous variables were performed using t-tests and paired t-tests. Categorical variables, expressed as percentages, were analyzed using the chisquare test. Univariate linear regression analyses were performed to analyze contributing factors towards high IES-R-K score. All calculations were performed using SPSS 18.0 (SPSS Inc. Armonk, NY). $P<0.05$ was considered significant.

\section{Results}

Of the 89 HD patients, 67 (75.3\%) completed the questionnaires. Comparisons of respondents and nonrespondents are shown in Supplementary Table 1. There was no significant difference between the two groups. The participants' mean age was 62.6 years; 46 (68.7\%) were men, 31 (46.3\%) had diabetes, and $3(4.4 \%)$ had a history of cardiovascular disease. The mean isolation period following exposure was 14.8 days. Single room isolation was implemented for 40 (58.8\%) subjects; cohort isolation, for 20 (29.4\%); and self-imposed quarantine, for $8(11.8 \%)$ subjects. Figure 1 shows the prevalence of IES-R-K $\geqq 18$ by isolation method. A total of 12 (17.9\%) participants reported stress symptoms with IES$\mathrm{R}-\mathrm{K}$ scores exceeding cut-off point. Nine out of $40 \mathrm{pa}-$ tients $(22.5 \%)$ in a single-room isolation group, 3 of 19 patients $(15.8 \%)$ in a cohort-isolation group and none of the subjects in the self-imposed quarantine group were shown to have post-traumatic stress with IES-R-K $\geqq 18$. The prevalence rate of IES- $\mathrm{R}-\mathrm{K} \geqq 18$ did not differ significantly $(P=0.3)$ between the single-room and cohortisolation groups. Table 1 shows a comparison of participants by IES-R-K cutoff point. Women and patients who had a shorter duration of isolation were more likely to develop symptoms of IES-R-K $\geqq 18$.

We performed linear regression analysis to identify associated factors with high IES-R-K score (Table 2). Shorter isolation period was associated with high IESR-K score (standardized $\beta$ coefficient $-0.272, \quad P=$ 0.026). We compared the total IES-R-K and subscale scores according to isolation duration in Table 3 . The total scores did not differ significantly between male and female subjects $(8.46 \pm 9.59$ vs. $12.38 \pm 12.09, P=$ $0.158)$. However, the sleep disturbance subscale score was higher among female, compared to male subjects $(1.57 \pm 2.79$ vs. $0.46 \pm 1.17, P=0.024)$. We divided the participants by median isolation duration. Participants isolated for less than 16 days showed a higher total score than those isolated for more than 16 days (13.47 \pm 12.69 vs. $6.23 \pm 6.45, P=0.004)$. At a subscale level, avoidance ( $4.94 \pm 5.94$ vs. $2.34 \pm 3.12, P=0.027)$ and sleep disturbance, emotional numbing, and dissociation $(4.75 \pm 3.25$ vs. $2.09 \pm 2.28, \quad P<0.001)$ subscale scores were higher in participants who had been isolated for less than 16 days. With regard to the sleep disturbance, emotional numbing, and dissociation subscale scores, emotional numbing $(2.22 \pm 1.50$ vs. $1.0 \pm 1.16, P<0.001)$ and dissociation $(1.50 \pm 1.59$ vs. $0.49 \pm 0.92, P=0.002)$ scores were higher in that group.

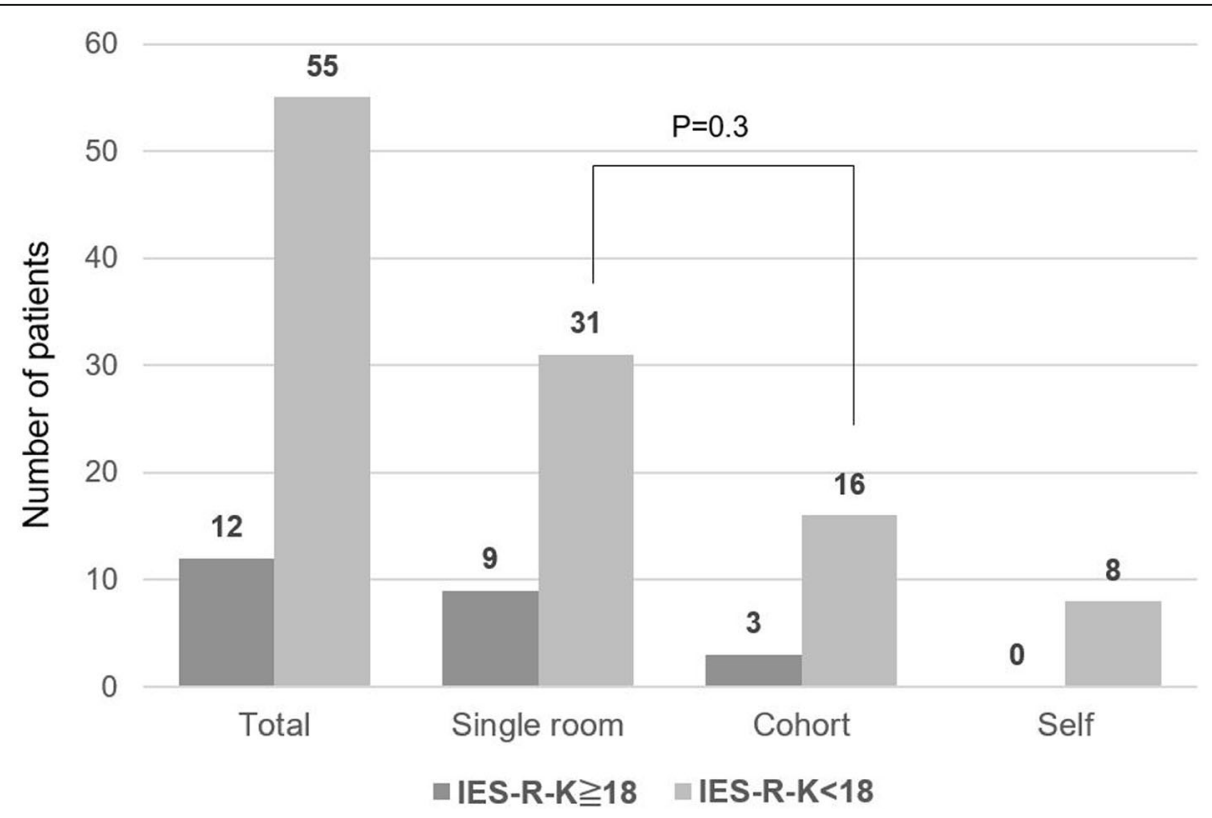

Fig. 1 Prevalence of IES-R-K score $\geqq 18$ in hemodialysis patients 1 year after MERS-CoV exposure 
Table 1 Baseline characteristics of participants according to IESR-K score

\begin{tabular}{|c|c|c|c|}
\hline Variables & $\begin{array}{l}\mid \mathrm{ES}-\mathrm{R}-\mathrm{K} \geqq 18 \\
N=12\end{array}$ & $\begin{array}{l}\text { IES-R-K }<18 \\
N=55\end{array}$ & $P$-value \\
\hline Age (year) & $59.4 \pm 11.4$ & $63.3 \pm 13.3$ & 0.4 \\
\hline Female, N (\%) & $7(58.3)$ & $14(25.5)$ & 0.03 \\
\hline Body mass index $\left(\mathrm{kg} / \mathrm{m}^{2}\right)$ & $22.7 \pm 4.2$ & $23.0 \pm 3.1$ & 0.8 \\
\hline Hemodialysis duration (months) & $47.2 \pm 46.4$ & $62.1 \pm 62.6$ & 0.4 \\
\hline Diabetes, N (\%) & $7(58.3)$ & $24(43.6)$ & 0.4 \\
\hline Previous cardiovascular disease, N (\%) & $1(8.3)$ & $2(3.6)$ & 0.5 \\
\hline \multicolumn{4}{|l|}{ Marital status $^{\mathrm{a}}$} \\
\hline Married & $6(75)$ & $31(81.6)$ & 0.7 \\
\hline Single or divorced & $2(25)$ & $7(18.4$ & \\
\hline History of psychiatric consultation ${ }^{a}$ & $1(12.5)$ & $1(2.6)$ & 0.2 \\
\hline Family history of psychopathology ${ }^{a}$ & $0(0)$ & $1(2.6)$ & 0.6 \\
\hline \multicolumn{4}{|l|}{ Laboratory data } \\
\hline Hemoglobin (g/dl) & $10.2 \pm 1.2$ & $10.4 \pm 1.0$ & 0.7 \\
\hline Albumin $(g / d l)$ & $3.8 \pm 0.5$ & $3.7 \pm 0.5$ & 0.7 \\
\hline $\mathrm{hsCRP}(\mathrm{mg} / \mathrm{dl})$ & $4.0 \pm 5.7$ & $5.6 \pm 8.0$ & 0.7 \\
\hline \multicolumn{4}{|l|}{ Isolation } \\
\hline Single room isolation, $\mathrm{N}(\%)$ & $9(75)$ & $31(56.4)$ & 0.3 \\
\hline Cohort isolation, N (\%) & $3(25)$ & $16(29.1)$ & \\
\hline Self-quarantine, N (\%) & $0(0)$ & $8(14.5)$ & \\
\hline Isolation duration (days) & $13.0 \pm 2.8$ & $15.2 \pm 3.0$ & 0.02 \\
\hline
\end{tabular}

Data expressed as mean (standard deviation) and number (percentage) ${ }^{a} 46$ of 67 subjects could be evaluated

Before the outbreak of MERS, $5.9 \%$ of the participants $(n=4)$ had scores exceeding the cutoff point of the IES$\mathrm{R}-\mathrm{K}$. We did not have pre-MERS IES-R-K scores for 23 respondents. Therefore, a paired-samples t-test was conducted to compare pre- and post-MERS IES-R-K scores in only 44 respondents (Table 4). Participants' post-traumatic stress symptoms increased at 1 year after the MERS outbreak. There was a significant difference in the total scores on the IES-R-K pre- and post-MERS $(3.16 \pm 9.02$ vs. $9.69 \pm 10.50, P<0.001)$. At the subscale

Table 2 Linear regression analysis for IES-R-K score

\begin{tabular}{lll}
\hline Variables & Univariate & \\
\cline { 2 - 3 } & $\begin{array}{l}\text { Standardized } \\
\beta \text { Coefficient }\end{array}$ & $P$-value \\
\hline Age (year) & -0.119 & 0.336 \\
Female & 0.175 & 0.158 \\
DM & 0.091 & 0.464 \\
BMl $\left(\mathrm{kg} / \mathrm{m}^{2}\right)$ & -0.07 & 0.579 \\
Dialysis duration (month) & -0.133 & 0.284 \\
Isolation duration (day) & -0.272 & 0.026 \\
Albumin (g/dl) & 0.024 & 0.875 \\
\hline
\end{tabular}

Abbreviations: DM Diabetes mellitus, BMI Body mass index level, sleep disturbance, emotional numbing, and dissociation at post-MERS $(2.52 \pm 2.61)$ was significantly higher than that at pre-MERS $(0.82 \pm 2.40, P<0.001)$. However, there was no significant difference in avoidance, intrusion, and hyperarousal at pre-MERS and post-MERS. When the fourth factor, which consists of three different symptoms, is broken down, there was a significant difference in emotional numbing $(0.27 \pm 0.85$ vs. $1.16 \pm 1.18$, $P<0.001)$ and dissociation $(0.20 \pm 0.67$ vs. $0.55 \pm 0.93$, $P=0.01)$ at pre- and post-MERS. However, sleep disturbance showed no significant difference $(0.34 \pm 1.36$ vs. $0.82 \pm 7.80, P=0.07)$.

\section{Discussion}

The present study examined post-traumatic stress symptoms from the quarantine experience of HD patients during the outbreak of MERS-CoV in Korea. In total, $17.9 \%$ of the patients developed stress symptoms with scores over the IES-R-K cut-off. Several studies have reported the psychological impact of the quarantine experience [13, 14]. Reynolds et al. showed that of the feelings experienced during SARS quarantine, boredom (62.2\%), isolation (60.6\%), and frustration (58.5\%) were most commonly reported. In that study, an IES-R score of at least 20 was obtained by $14.6 \%$ of respondents [14]. In a study on the psychological effects of SARS quarantine in Toronto, the 129 quarantined persons who responded to a Web-based survey exhibited a high prevalence of psychological distress [13]. Symptoms of PTSD and depression were observed in 28.9 and $31.2 \%$ of respondents, respectively. In these studies, quarantine type was home or work. Subjects were not hospitalized.

The results of this study revealed that isolation duration is negatively associated with IES-R-K score. This result is contrary to those of previous studies that showed a positive correlation between quarantine duration and post-traumatic stress symptoms [13, 14]. However, isolation duration does not mean duration only, but also represents participants' cooperativeness with the mandatory quarantine request. When HD patients who were exposed to MERS-CoV were asked to undergo mandatory quarantine, some were cooperative, such that they were admitted immediately following instructions by medical staff. Others resisted the isolation, dragging on until, finally, they were forcibly hospitalized at a later stage. Since all participants were later released from quarantine on the same day, the isolation duration indicated their cooperativeness with the mandatory quarantine and their trust in the prevention system of epidemics. Therefore, the results of this study indicated that participants who cooperated with the isolation request and received longer support reported fewer posttraumatic stress symptoms. At the subscale level, patients quarantined for less than 16 days showed higher 
Table 3 IES-R-K score among study respondents $(N=67)$

\begin{tabular}{|c|c|c|c|c|c|c|}
\hline & \multicolumn{2}{|l|}{ Total } & \multicolumn{2}{|l|}{ Sex } & \multicolumn{2}{|c|}{ Isolation Duration } \\
\hline & & & $\begin{array}{l}\text { Male } \\
N=46\end{array}$ & $\begin{array}{l}\text { Female } \\
N=21\end{array}$ & $\begin{array}{l}\geqq 16 \text { days } \\
N=35\end{array}$ & $\begin{array}{l}<16 \text { days } \\
N=32\end{array}$ \\
\hline & Mean (SD) & $95 \% \mathrm{Cl}$ & Mean (SD) & Mean (SD) & Mean (SD) & Mean (SD) \\
\hline Total IES-R-K score & $9.69(1.28)$ & $7.36-12.33$ & $8.46(9.59)$ & $12.38(12.09)$ & $6.23(6.45)^{+}$ & $13.47(12.69)^{+}$ \\
\hline \multicolumn{7}{|l|}{ IES-R subscales } \\
\hline Avoidance subscale & $3.58(0.59)$ & $2.41-4.54$ & $3.26(4.76)$ & $4.29(5.01)$ & $2.34(3.12)^{+}$ & $4.94(5.94)^{+}$ \\
\hline Intrusion subscale & $1.78(0.38)$ & $0.97-2.59$ & $1.54(2.77)$ & $2.29(3.77)$ & $1.31(1.76)$ & $2.28(4.08)$ \\
\hline Hyperarousal subscale & $0.97(0.27)$ & $0.48-1.63$ & $0.65(1.98)$ & $1.67(2.63)$ & $0.49(1.22)$ & $1.50(2.91)$ \\
\hline Sleep disturbance, emotional numbing, and dissociation subscale & $3.36(0.38)$ & $2.62-4.18$ & $3.00(2.76)$ & $4.14(3.61)$ & $2.09(2.28)^{++}$ & $4.75(3.25)^{++}$ \\
\hline - Sleep disturbance & $0.81(0.23)$ & $0.36-1.23$ & $0.46(1.17)^{+}$ & $1.57(2.79)^{+}$ & $0.60(1.54)$ & $1.03(2.21)$ \\
\hline - Emotional numbing & $1.58(0.18)$ & $1.15-1.98$ & $1.57(1.51)$ & $1.62(1.36)$ & $1.00(1.16)^{++}$ & $2.22(1.50)^{++}$ \\
\hline - Dissociation & $0.97(0.17)$ & $0.68-1.29$ & $0.98(1.44)$ & $0.95(1.24)$ & $0.49(0.92)^{+}$ & $1.50(1.59)^{+}$ \\
\hline
\end{tabular}

avoidance, emotional numbing, and dissociation, compared to those quarantined for more than 16 days.

Psychological trauma causes not only post-traumatic stress symptoms such as intrusion, avoidance, and hyperarousal, but also many other somatic and psychiatric symptoms due to its complexity and the diversity of symptoms, showing high levels of comorbidity with other problems [15]. Based on Lee [16] suggestion regarding posttraumatic growth, trauma-related symptoms occur in sequential order, as follows: catatonia, emotional numbing, dissociation, fear, intrusion, paranoid ideation, avoidance, obsession, hyperarousal, anxiety, depression, existential emptiness, searching for meaning, and posttraumatic growth. The results of the current study, indicating that participants showed emotional numbing and dissociation more often, compared to intrusion, avoidance, and hyperarousal, in turn indicated that participants did not process the trauma and the isolation experience, so that their symptoms remained at the very early stage of processing trauma. This indicates that participants can experience subsequent symptoms of hyperarousal. Thus, psychological intervention and follow-up are needed.
In this study, being female was associated with posttraumatic stress symptoms. This is consistent with previous research that found gender differences in traumatized populations [17-20]. Specifically, the score on the sleep disturbance subscale was higher among female subjects. Before the outbreak of MERS, 5.9\% of participants $(n=4)$ reported that they had pre-existing posttraumatic stress symptoms exceeding the cutoff point of the IES-R-K. This is higher than the current prevalence in the general population of a city in Korea (2.12\%) [21]. This seems to be because the study sample comprised patients with $\mathrm{HD}$, who are going through a lifethreatening chronic disease.

There are several limitations in this study. First, this study had a low response rate and a small sample size. Therefore, the present findings may not be readily generalized to all isolated HD patients. Second, the IES$\mathrm{R}-\mathrm{K}$ is a self-report instrument tested 12 months after subjects' exposure to MERS-CoV. Recall may have been affected and could have an impact on the reported results. Furthermore, other factors in addition to isolation experience might affect psychological stress in

Table 4 IES-R-K score change before and after exposure to MERS-CoV $(N=44)$

\begin{tabular}{|c|c|c|c|c|c|}
\hline IES-R-K & $\mathrm{N}$ & Before & After & t & $P$-value \\
\hline Hyperarousal & 44 & $0.68 \pm 2.39$ & $0.91 \pm 1.84$ & -0.57 & 0.6 \\
\hline Intrusion & 44 & $0.98 \pm 2.87$ & $1.93 \pm 2.97$ & -1.88 & 0.07 \\
\hline Avoidance & 44 & $1.93 \pm 4.69$ & $3.32 \pm 4.11$ & -1.90 & 0.06 \\
\hline Sleep disturbance, emotional numbing, and dissociation & 44 & $0.82 \pm 2.40$ & $2.52 \pm 2.61$ & -4.52 & $<0.001$ \\
\hline Sleep disturbance & 44 & $0.34 \pm 1.36$ & $0.82 \pm 1.80$ & -1.87 & 0.07 \\
\hline Emotional numbing & 44 & $0.27 \pm 0.85$ & $1.16 \pm 1.18$ & -4.66 & $<0.001$ \\
\hline Dissociation & 44 & $0.20 \pm 0.67$ & $0.55 \pm 0.93$ & -2.71 & 0.01 \\
\hline Total & 44 & $3.16 \pm 9.02$ & $9.69 \pm 10.50$ & -4.73 & $<0.001$ \\
\hline
\end{tabular}

Data expressed as mean (standard deviation)

Cases with missing values were excluded from the analysis 
quarantined HD patients. Third, we had no information about subjects' education level. Fourth, we did not measure other psychological and medical factors that could affect post-traumatic stress symptoms 12 months after isolation. Fifth, we didn't investigate stress symptoms on HD patients without isolation as a control.

Despite these limitations, the results of this study show that quarantine can result in considerable psychological distress.. A shorter duration of quarantine was associated with high IES-R-K scores. Public health officials, infectious disease physicians, and psychologists must be aware of this result. Further research is needed to determine factors that influence the success of quarantine and in relation to the provision of additional support to patients who are at an increased risk of the adverse psychological effects of quarantine.

\section{Supplementary information}

Supplementary information accompanies this paper at https://doi.org/10. 1186/s13030-020-00181-z.

Additional file 1: Table S1. Comparison of study respondents with non-respondents.

\section{Acknowledgements}

Not applicable.

\section{Authors' contributions}

AJC, HSL, YKL and AKW analyzed and interpretation the patient data. AJC and YKL was a major contributor in writing the manuscript. HJJ, HCP, DWJ, YGK, CHL, KDY and SHL made substantial contribution to the conception and design of the work. The author(s) read and approved the final manuscript.

\section{Funding}

This work was supported by a grant from the Korean Healthcare Technology R\&D Project through the Korea Health Industry Development Institute (KHIDI), funded by the Ministry of Health \& Welfare, Republic of Korea (grant number: HI15C3227)

\section{Availability of data and materials}

All data generated or analyzed during this study are included in this published article and its supplementary information files.

\section{Ethics approval and consent to participate}

This study was approved by the Institutional Review Boards of Kangnam Sacred Heart Hospital (IRB No. 2015-11-134). Written informed consent was obtained from all patients before enrollment.

\section{Consent for publication}

Not applicable.

\section{Competing interests}

The authors declare that they have no competing interests.

\section{Author details}

${ }^{1}$ Department of Internal Medicine, Kangnam Sacred Heart Hospital, Hallym University College of Medicine, 1, Singil-ro, Yeongdeungpo-gu, Seoul 07441 South Korea. ${ }^{2}$ Hallym University College of Medicine, Psychiatry, Seoul, Republic of Korea. ${ }^{3}$ Department of Internal Medicine, Armed Forces Capital Hospital, Seongnam, South Korea. ${ }^{4}$ Internal Medicine, Kyung Hee University at Kangdong, Seoul, Republic of Korea. ${ }^{5}$ Gangeung Medical Center, Anesthesiology, Gangeung, Republic of Korea. ${ }^{6}$ Internal Medicine, Ulsan University Hospital, Ulsan, Republic of Korea.
Received: 13 October 2019 Accepted: 23 March 2020

Published online: 15 April 2020

\section{References}

1. Chua SE, Cheung V, Cheung C, MCAlonan GM, Wong JW, Cheung EP, et al. Psychological effects of the SARS outbreak in Hong Kong on high-risk health care workers. Can J Psychiatr. 2004;49(6):391-3.

2. Wu KK, Chan SK, Ma TM. Posttraumatic stress after SARS. Emerg Infect Dis. 2005;11(8):1297.

3. Au A, Chan I, Li P, Chan J, Chan Y, Ng F. Correlates of psychological distress in discharged patients recovering from severe acute respiratory syndrome in Hong Kong. Int J Psychosoc Rehabil. 2004;8:41-51.

4. Cheng SK, Wong C, Tsang J, Wong K. Psychological distress and negative appraisals in survivors of severe acute respiratory syndrome (SARS). Psychol Med. 2004:34(7):1187-95.

5. Mak IWC, Chu CM, Pan PC, Yiu MGC, Ho SC, Chan VL. Risk factors for chronic post-traumatic stress disorder (PTSD) in SARS survivors. Gen Hosp Psychiatry. 2010;32(6):590-8.

6. Chen C-K, Tsai Y-C, Hsu H-J, Wu I-W, Sun C-Y, Chou C-C, et al. Depression and suicide risk in hemodialysis patients with chronic renal failure. Psychosomatics. 2010;51(6):528-. e6.

7. Levy NB. Psychological problems of the patient on hemodialysis and their treatment. Psychother Psychosom. 1979;31(1-4):260-6.

8. Tagay S, Kribben A, Hohenstein A, Mewes R, Senf W. Posttraumatic stress disorder in hemodialysis patients. Am J Kidney Dis. 2007;50(4):594-601.

9. Breslau N, Chilcoat HD, Kessler RC, Davis GC. Previous exposure to trauma and PTSD effects of subsequent trauma: results from the Detroit area survey of trauma. Am J Psychiatry. 1999;156(6):902-7.

10. Park HC, Lee YK, Lee SH, Yoo KD, Jeon HJ, Ryu DR, et al. Middle East respiratory syndrome clinical practice guideline for hemodialysis facilities. Kidney Res Clin Pract. 2017;36(2):111-6.

11. Kim JY, Song JY, Yoon YK, Choi SH, Song YG, Kim SR, et al. Middle East respiratory syndrome infection control and prevention guideline for healthcare facilities. Infect Chemother. 2015;47(4):278-302.

12. Eun HJ, Kwon TW, Lee SM, Kim TH, Choi MRC, Cho SJ. A study on reliability and validity of the Korean version of impact of event scale-revised. J Korean Neuropsychiatr Assoc. 2005;44(3):303-10.

13. Hawryluck L, Gold WL, Robinson S, Pogorski S, Galea S, Styra R. SARS control and psychological effects of quarantine, Toronto, Canada. Emerg Infect Dis. 2004;10(7):1206-12.

14. Reynolds DL, Garay JR, Deamond SL, Moran MK, Gold W, Styra R. Understanding, compliance and psychological impact of the SARS quarantine experience. Epidemiol Infect. 2008;136(7):997-1007.

15. Rosenbaum L. Post-traumatic stress disorder: the chameleon of psychiatry. Nord J Psychiatry. 2004;58(5):343-8.

16. Lee HS. From trauma to growth: posttraumatic growth clock. Korean J Cogn Sci. 2016;27(4):501-39.

17. Olff M, Langeland W, Draijer N, Gersons BP. Gender differences in posttraumatic stress disorder. Psychol Bull. 2007;133(2):183.

18. Joseph S, Linley PA, Andrews L, Harris G, Howle B, Woodward C, et al. Assessing positive and negative changes in the aftermath of adversity: psychometric evaluation of the changes in outlook questionnaire. Psychol Assess. 2005;17(1):70.

19. Park CL, Cohen LH, Murch RL. Assessment and prediction of stress-related growth. J Pers. 1996;64(1):71-105.

20. Tedeschi RG, Calhoun LG. The posttraumatic growth inventory: measuring the positive legacy of trauma. J Trauma Stress. 1996;9(3):455-71.

21. Eun HJ, Lee SM, Kim TH. The epidemiological study of posttraumatic stress disorder in an urban area. J Korean Neuropsychiatr Assoc. 2001;40(4):581.

\section{Publisher's Note}

Springer Nature remains neutral with regard to jurisdictional claims in published maps and institutional affiliations. 